UDC 519.6

$10.23947 / 2587-8999-2021-1-1-1-9$

\title{
SUSPENSIONS TRANSPORT PREDICTIVE MODELING UNDER VARIOUS SCENARIOS OF FERROMANGANESE NODULES EXTRACTION FROM THE PACIFIC OCEAN BOTTOM
}

\author{
A. I. Sukhinov' , A. A. Sukhinov², S. B. Kirilchik² \\ ${ }^{1}$ Don State Technical University, Rostov-on-Don, Russia \\ ${ }^{2}$ Southern Federal University (branch), Gelendzhik, Russia
}

$\square$ sukhinov@gmail.com

The article is devoted to the suspensions' distribution mathematical modeling in the Eastern Pacific Ocean for various scenarios for the ferromanganese nodules extraction. The suspensions propagation model with complex granulometric composition that can interact in an aqueous medium takes into account the suspensions microturbulent diffusion caused by the turbulent aqueous medium movement and the suspensions convection caused by the advective movement of water mass in the ocean; gravitational suspensions deposition under the gravity influence; mutual transitions between different fractions that make up the suspension; interaction of particles with the bottom and with the free surface.

Keywords: ferromanganese nodules, suspensions gravitational deposition, microturbulent diffusion, advective motion

Introduction. The world's oceans are beginning to play an increasing role in environmental and climatological problems on Earth. This is due, in particular, to the exhaustion of the mineral resources of the land and the transition to intensive development of the minerals of the World Ocean. More than 100 years ago, deposits of iron-manganese nodules (IMN) were discovered, which contain more than 30 elements of the periodic table, most of which are extremely rare on land on an industrially significant scale. With the development of technology, the problem of industrial production of IMN, which becomes economically feasible, has become on the agenda.

It is well known that the study of issues related to the consequences of industrial extraction of minerals from the ocean floor, in particular, iron-manganese nodules (IMN), is an important scientific and practical problem that is in the focus of the world scientific community.

The impact of oil and gas extraction on the ocean ecosystem is a complex multifactorial process. Since the 70s of the twentieth century, experimental studies have been conducted in the areas of the IMN location, primarily in the eastern Pacific Ocean, in particular, using deep-sea equipment to study the effects of silt agitation and assess the consequences of mining. At the same time, largescale field experiments are not only expensive, but also dangerous. 
Mathematical modeling of the suspensions distribution in the Eastern Pacific Ocean for various scenarios will reduce, and in some cases, eliminate large-scale and unsafe field experiments.

The use of high-quality mathematical models built on the basis of accumulated oceanological data is currently reliable and safe methodology for forecasting the Ocean ecosystem.

The suspensions propagation model having complex granulometric composition, capable of interacting in an aqueous medium, takes into account the suspensions microturbulent diffusion caused by the aqueous medium turbulent movement and the suspensions convection caused by the circulating (advective) movement of water mass in the ocean; suspensions gravitational deposition (under the gravity influence); mutual transitions between different fractions that make up the suspension (the combination of particles into larger ones and their decay); the interaction of particles with the bottom and with the free surface.

Let's find out the parameters of the particles released into the ocean, assuming that the particles that were raised from the bottom are thrown out from the vessel extracting nodules. Figure 1 shows the maps of the granulometric composition of the bottom.

(A) SAND FRACTION $(1,0-0,1 \mathrm{~mm})$

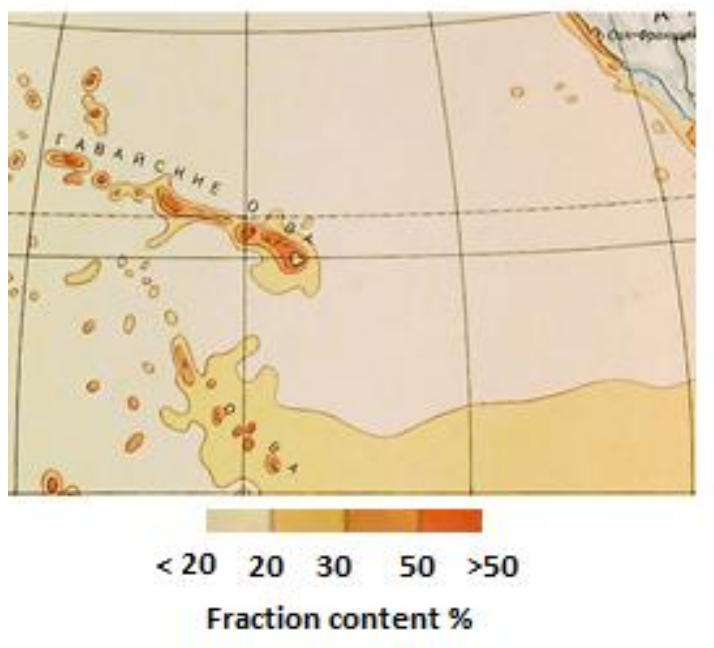

(b) SUBCOLLOID FRACTION (<0.001 mm)

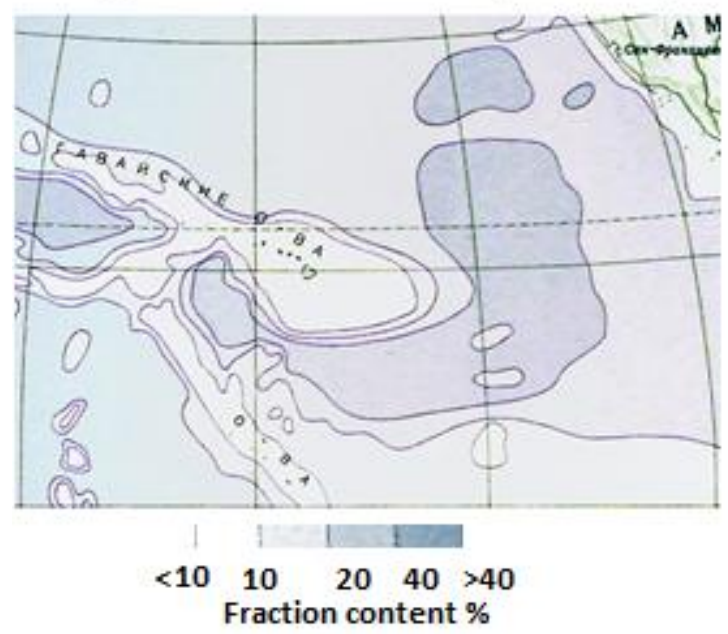

(b) SILTSTONE FRACTION $(0,1-0,001 \mathrm{~mm})$

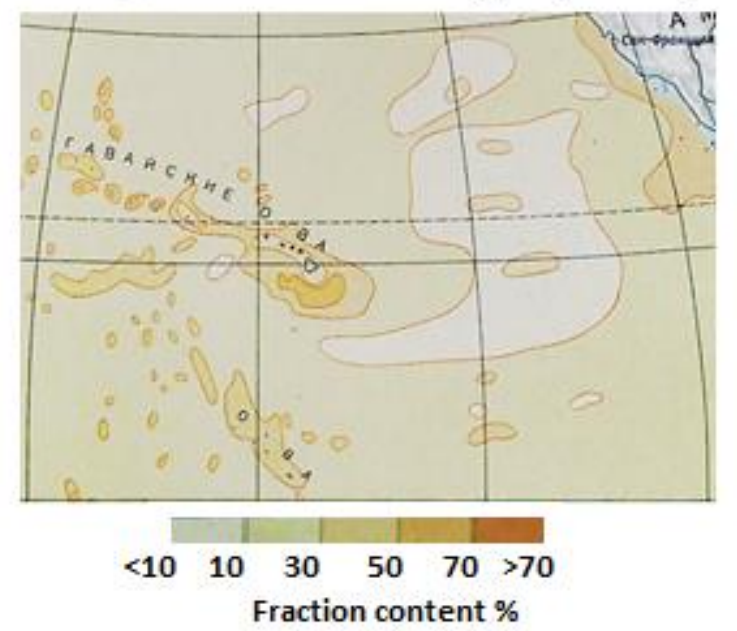

(A) PELITE FRACTION $(<0.01 \mathrm{~mm})$

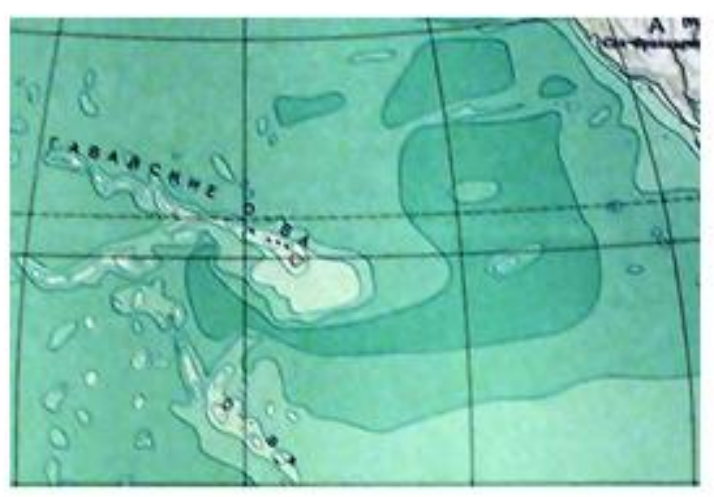

$<10 \begin{array}{lllll}10 & 30 & 50 & 70 & 90\end{array}>90$

Fraction content \%

Fig. 1. Bottom sediments granulometric composition 
The system of equations describing the behavior of particles will look like this:

$$
\left\{\begin{array}{l}
\frac{\partial c_{i}}{\partial t}+u \frac{\partial c_{i}}{\partial x}+v \frac{\partial c_{i}}{\partial y}+\left(w-w_{g i}\right) \frac{\partial c_{i}}{\partial z}=\mu_{i}\left(\frac{\partial^{2} c_{i}}{\partial x^{2}}+\frac{\partial^{2} c_{i}}{\partial y^{2}}\right)+v_{i} \frac{\partial^{2} c_{i}}{\partial z^{2}}+f_{i}, \quad i=1, \ldots, N \\
f_{1}=\left(\alpha_{2} c_{2}-\beta_{1} c_{1}\right)+\Phi_{1}(x, y, z, t), \\
\cdots \\
f_{i}=\left(\beta_{i-1} c_{i-1}-\alpha_{i} c_{i}\right)+\left(\alpha_{i+1} c_{i+1}-\beta_{i} c_{i}\right)+\Phi_{i}(x, y, z, t), \\
\cdots \\
f_{N}=\left(\beta_{N-1} c_{N-1}-\alpha_{N} c_{N}\right)+\Phi_{N}(x, y, z, t) .
\end{array}\right.
$$

where $N$ is the number of types of particles, $c_{i}$ is the concentration of particles of the $i$-th type, $u, v$, $w$ are the fluid velocity vector components, $w_{g i}$ is the rate of gravitational deposition of particles of the type $i-t h, \mu_{i}, v_{i}$ are the coefficients of horizontal and vertical turbulent diffusion of particles of the $i$-th type, $\alpha_{i} \geq 0, \beta_{i} \geq 0$ are the rates of transformation of particles of the $i$-th type into the $i-1$-th and $i+1$-th type, respectively, $\Phi_{i}$ is the power of particle sources of the type $i$-th.

The terms in the left part (except for the time derivative) describe the convection of particles: their transport under the influence of fluid flow and gravity. The terms in the right part describe the diffusion of suspensions caused by the presence of vortex motions of various scales in the aqueous medium and the transformation of particles from one type to another. It should be noted that the physical mechanisms of microturbulent diffusion differ significantly from the mechanisms of diffusion of an ensemble of particles in a vacuum or diffusion processes in solids. Microturbulent diffusion, which should more naturally be called the «process of turbulent concentration equalization», is caused by the involvement of particles in the movement of constantly existing turbulent vortices that have different spatiotemporal scales. Depending on how long the observation (measurement) process is, vortices of increasingly large scales are essential in this process, from sizes of the order of millimeters to thousands of meters or more. In the model, this fact is taken into account by using diffusion coefficients averaged for processes with scales of hundreds to thousands of kilometers, with a duration of hundreds of hours

The vertical diffusion coefficient is chosen to be different from the horizontal diffusion coefficient due to the fact that the effect of the difference of these coefficients is often observed in different media and can be caused by various factors. Fig. 2 shows the particles of different fractions mutual transitions process, taking the strictly sequential particles transformation mechanism as the most probable.

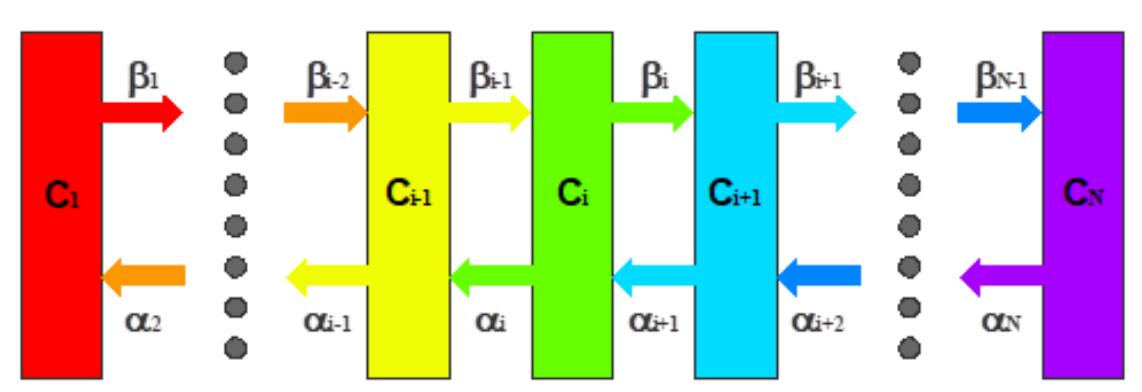

Fig. 2. Particles of various types transformation diagram 
An inconsistent transformation would require the introduction of a transformation matrix, which would complicate the model without significantly expanding its scope.

Add the initial and boundary conditions to the system (1) (assume that the deposition of particles to the bottom is irreversible):

$$
\begin{gathered}
c_{i}(x, y, z, 0)=c_{i}^{0}(x, y, z), i=1,2, \ldots, N \\
\forall\left(x_{0}, y_{0}, z_{0}\right) \in V: B\left(x_{0}, y_{0}, z_{0}\right) \geq 0 \Rightarrow c_{i}(x, y, z, t)=0, \\
\left.\frac{\partial c}{\partial x}\right|_{x=0}=0,\left.\quad \frac{\partial c}{\partial x}\right|_{x=H_{x}}=0,\left.\quad \frac{\partial c}{\partial y}\right|_{y=0}=0,\left.\quad \frac{\partial c}{\partial y}\right|_{y=H_{y}}=0,\left.\quad \frac{\partial^{2} c}{\partial z^{2}}\right|_{z=0}=0
\end{gathered}
$$

To assess the characteristic scale of hydrothermodynamic processes associated with the discharge of bottom water during the extraction of IMN, consider the hydrothermodynamic processes associated with the most likely technological scheme of production [1]. Simplistically, it can be assumed that there is a direct suction of red silts on which the nodules are located when sufficiently powerful pumps are operating and the resulting pulp is fed up through a flexible pipeline to the processing vessel, where the resulting mixture is separated, the nodules are washed with seawater. Further, the nodules can be reloaded onto a transport vessel for delivery to a processing enterprise. At the same time, production waste is removed, which is a mixture of silt and cold bottom water. It should be expected that, with the exception of the largest particles, the bulk of the waste is a suspension with a complex granulometric composition $[2,3,4]$. The consequences of the impact of mining on the bottom space associated with the erosion of the bottom and the oppression of benthic communities will be felt at distances of tens of kilometers due to a sufficiently developed system of bottom currents in the area of the Clarion-Clipperton province. This is evidenced by numerous experiments with distillers conducted in this area in the seventies and nineties of the XX century [5].

The main attention should be paid to the consideration of the impact of the disposal of technological waste, since the most cost-effective scheme for their disposal is direct discharge into the near-surface layer of the ocean. The most obvious damage is a change in the physical and chemical properties of the active layer of the ocean: a decrease in the temperature of the aquatic environment, an increase in its turbidity, a change in the composition and concentration of nutrient salts and, as a result, a decrease in the number and a change in the species composition of plankton populations. Therefore, the influence of physical processes accompanying waste disposal on the active layer of the ocean is considered. The objective characteristics of such an influence can be considered a change in temperature, a significant increase in the concentration of suspensions and a decrease in the transparency of the ocean photic layer.

For simplicity, assume that the extraction process is accompanied by a change in the temperature of the surface layer of ocean water to values close to those of the aquatic environment in the bottom region. Let's estimate the characteristic scale of these processes. Let $h$ be the thickness of the cooled layer, the temperature of which is approximately assumed to be equal to the temperature of the bottom water $T_{b}$. Being more dense in relation to the surrounding near-surface water, the bottom water begins to fall through. The resulting turbulent and convective exchanges can have a rather complex structure. At the same time, the temperature is equalized due to heat exchange. Considering that the turbulent exchange makes a greater contribution, we neglect the heat exchange. Such a simplification may give overestimated estimates of the temperature equalization time. Indirectly, we 
will take into account the fact of temperature equalization by introducing a density gradient in the vertical direction in a column of liquid with a height of $h$ :

$$
\gamma=\partial \rho / \partial z
$$

Then the potential energy of the volume of liquid enclosed in a column of liquid height $\mathrm{h}$ with a unit mass, due to the density gradient, will be equal to:

$$
W_{p}=g h^{2} / 12 \rho_{0},
$$

where $\rho_{o}$ is the average water density over the volume of a column with height $h$. Here, $h$ means a layer of water consisting largely of cold bottom water, which was formed near the surface due to discharge from the technological (mining) complex. We will assume that its thickness is about 10 meters, and the temperature difference compared to the surrounding waters is about 10 degrees Celsius. We will assume that the lowering of heavier particles of bottom water is accompanied by the dissipation of potential energy associated with overcoming viscous forces, and more precisely, the potential energy is converted into the energy of microturbulent motion of the water medium, which can be estimated for a single volume of a liquid column as follows:

$$
W_{c}^{1}=-\frac{\partial}{\partial z}\left(k(z) \frac{\partial w}{\partial z}\right)
$$

where $k(z)$ is the coefficient of turbulent exchange in vertical direction.

We integrate both parts of equality (6) in $z$, from 0 to, to $H_{T}$ determine the total kinetic energy dissipation $W_{c}$, where $H_{T^{0}}$ is the depth relative to the undisturbed surface on which the thermocline is located:

$$
W_{c}=\int_{0}^{H_{T}} W_{c}^{1} d z=-\int_{0}^{H_{T}} \frac{\partial}{\partial z}\left(k(z) \frac{\partial w}{\partial z}\right) d z
$$

which leads to equality:

$$
W_{c}=-\left.k(z) \frac{\partial w}{\partial z}\right|_{0} ^{H_{T}}
$$

Assume that at the depth of the thermocline, the coefficient of turbulent exchange has such small values that it can be considered equal to zero, i.e. $k\left(H_{T}\right)=0$.

Taking into account this assumption, equality (7) is written:

$$
W_{c}=k(0) \frac{\partial w(0)}{\partial z}
$$

Assuming that $W_{p}=W_{c}$ from the relations (5) and (8) we obtain:

$$
\frac{\partial w(0)}{\partial z}=\frac{g \gamma h^{2}}{12 \rho_{0} k(0)}
$$

To estimate the time of lowering of the bottom water particles, we can assume that the velocity $w(z)$ first increases linearly to the value $w_{\max }$, and then decreases linearly to the value $w_{0}$ depending on the $z$ coordinate. Taking into account the relation (9), it is not difficult to write down the formula defining the function $w=w(z)$ :

$$
w(z)=\left\{\begin{array}{c}
w_{o}+\alpha \cdot z, \quad 0 \leq z \leq 0.5 H_{T} \\
\alpha\left(H_{T}-z\right)+w_{0}, \quad 0.5 H_{T}<z \leq H_{T}
\end{array} \quad, \text { where } \quad \alpha=\frac{g \gamma h^{2}}{12 \rho_{0} k(0)}\right.
$$


Estimate the actual time of lowering the water particles:

$$
T_{f}=2 \cdot \int_{0}^{0.5 H_{T}} \frac{d z}{w(z)} .
$$

Based on the last equality and relation (10), and, performing the obvious integration, obtain:

$$
T_{f}=\frac{2}{\alpha} \ln \left(1+\frac{0.5 \cdot \alpha H_{T}}{w_{0}}\right), \quad \alpha=\frac{g \gamma h^{2}}{12 \rho_{0} k(0)},
$$

To estimate the characteristic orders, take the following constant values in relations (11):

$h=10 \mathrm{~m}, \gamma / \rho_{0}=\left(300 \cdot 10^{-6} 1 / \mathrm{deg}\right) \cdot 1(\mathrm{deg} / \mathrm{m}), w_{0}=10^{-5} \mathrm{~m} / \mathrm{s}$.

$k(0)=10 \mathrm{~m}^{2} / \mathrm{s}, H_{T}=500 \mathrm{~m}, g=10 \mathrm{~m} / \mathrm{s}^{2}$.

Then get:

$\alpha=0,0025, T_{f} \approx 8834 s$.

Taking into account the approximate nature of the conducted arguments, we will take the following estimate of the time of lowering of cold (bottom) water:

$$
T_{f} \approx 10000 \mathrm{~s} \text {. }
$$

For indirect verification of the obtained time estimate, we use a simplified approach based on the law of conservation of energy. We will assume that half of the potential energy of the bottom liquid raised up passes into the energy of microturbulent pulsations and, as a result, into heat, and the other half is converted into kinetic energy associated with the movement (lowering) of water masses vertically:

$$
\frac{1}{2}\left(\frac{g \gamma h^{2}}{12 \rho_{0}}\right)=\frac{w_{\max }^{2}}{2},
$$

where $w_{\max }$ is the maximum lowering speed. Expressing from the last relation $w_{\max }$ and, equating the characteristic rate of lowering $w$ to half of the maximum value, we get: $w=\frac{h}{2} \sqrt{\frac{\gamma g}{12 \rho_{0}}}$, where
$w \approx 2,5 \mathrm{~cm} / \mathrm{s}$.

Considering, as before, the characteristic depth of the thermocline equal to 500 meters, we get: $T_{f} \approx 2000 \mathrm{~s}$.

To estimate the characteristic spatial scales of phenomena leading to the transfer of bottom water masses in horizontal directions, medium-long-term data on currents are used, for example, from [6]. For this region of the Pacific Ocean, these speeds do not exceed 0,5 m/s. Consequently, the effect of cold water from a single sufficiently powerful source in the water layer from the surface to the thermocline will be felt at distances of no more than $10 \mathrm{~km}$. Thus, the spatiotemporal characteristics of the phenomena associated with the cold-water mass propagation raised during extraction from the bottom area of the ocean, which are of a small-scale nature and may not be taken into account when modeling.

Based on this analysis and the constructed models, algorithms and programs, numerical experiments were performed for model problems, as well as for the real problem of predicting the 
distribution of suspensions consisting of three fractions in the area of IMN production located in the Clarion-Clipperton ore-bearing province in the eastern Pacific Ocean.

The simulation results show that the counterflow located in the area of the proposed extraction of ferromanganese nodules can significantly reduce the amount of pollution by dumping the waste material not on the surface, but at a depth of about $100 \mathrm{~m}$.

In the Clarion-Clipperton area, three mining sites were set to track the distribution of suspensions depending on the location of the mining site. Modeling of the transport of three types of suspensions was performed for three different scenarios of dumping technological waste (suspensions) into the ocean: directly to the surface, at depths of 100 and 500 meters. The latter discharge option does not lead to large-scale contamination of the intended mining area. This development is indirectly supported by the fact that the first thermocline is located at these depths, near which the current velocities significantly attenuate. The results of numerical simulation for the first two reset scenarios are given below. The distribution of the siltstone fraction in Fig. 3 and 4 is shown in blue, the pelitic fraction in green, and the subcolloid fraction in red.
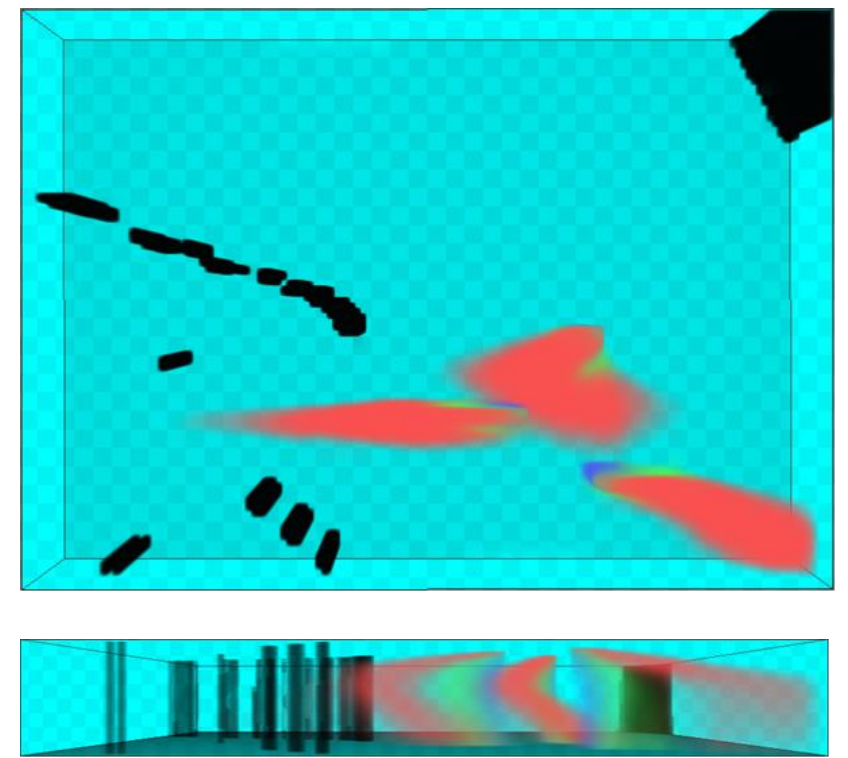

Fig. 3. The result of the discharge of suspensions into the ocean. The discharge is performed on the surface. The vertical scale has been increased by 100 times
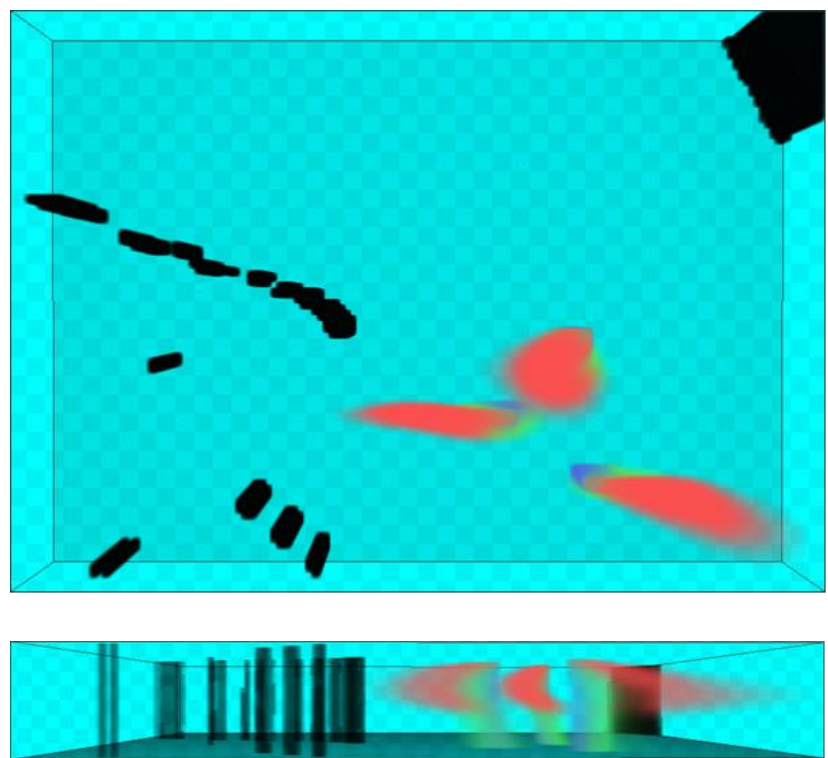

Fig. 4. The result of the discharge of suspensions into the ocean. The discharge is performed at a depth of 100 meters

It turned out that the sultan of suspensions is very sensitive to the place of discharge, which is directly connected with a particular mining site. For example, discharge in the area of the southeastern mining site leads to intensive transport of suspended matter to the area of the western coast of Central America. Detailed modeling of this scenario is beyond the scope of this work, since it requires calculating the dynamics and lithodynamics of the coastal zone of the ocean. At the same time, the discharge of suspensions at two other mining sites located to the northwest leads to a completely different picture of the spread of sultan, which rushes towards the Hawaiian Islands. As follows from the simulation results, those particles that did not have time to descend to depths of more than 300 meters, while reaching the offshore part of the Hawaiian Islands, continue to move in the direction of the coastline. The simulation results show that there are an overwhelming number of 
such particles from the two smallest fractions, if the depth of the technological waste discharge does not exceed 100 meters. At the same time, the particles of the siltstone fraction dropped to depths of 100 meters or more are picked up by the eastern counterflow and begin to move away from the Hawaiian Islands. As for other situations, for example, the dumping of siltstone particles at depths from 0 to 100 meters, additional field experiments are required to study this situation in order to obtain additional data on the real coefficients of microturbulent diffusion, refine their hydraulic fineness and increase the overall resolution of the constructed models.

\section{References}

1. Hein, James; Spinardi, Francesca; Okamoto, Nobuyuki; Mizell, Kira; Thorburn, Darryl; Tawake, Akuila (2015). "Critical metals in manganese nodules from the Cook Islands EEZ, abundances and distributions". Ore Geology Reviews. 68: 97-116

2. Sukhinov A. I., Kirilchik S. V. Assessment of the characteristic scales of hydrothermodynamic processes associated with the discharge of bottom waters in the ocean during the extraction of iron-manganese nodules // Collection of scientific papers of the 10th International Conference "Mathematical models of Physical processes". Taganrog, Publishing house of TSPI, 2004, pp. 198-202.

3. I. O. Leontiev. Coastal dynamics: waves, currents, sediment flows. Moscow: Geos,2001-272 p.

4. Atmospheric turbulence and modeling of impurity propagation. - Edited by F. T. M. Nyistad and H. Van Dopa - - L.:_Hydrometeoizdat, 1985 - - 352 p.

5. A.V. Koldoba, Yu. A. Poveshchenko, E. A. Samarskaya, V. F. Tishkin. Methods of mathematical modeling of the environment. - M.: Nauka, $2000-254$ p.

6. International Seabed Authority (2010). A Geological Model of Polymetallic Nodule Deposits in the Clarion-Clipperton Fracture Zone and Prospector's Guide for Polymetallic Nodule Deposits in the Clarion Clipperton Fracture Zone. Technical Study: No. 6.

7. Amos A.F. et al. Environmental aspects of nodule mining - - From book: Marine Manganese Deposits, Elsevier Oceanography Publ. Co. 1977, p. 391-439.

8. Atlas of the Oceans. The Pacific Ocean. Navy, 1974.

9. Kirilchik S. V. Mathematical modeling of the processes of distribution of suspensions in the ocean during mining //Dissertation for the degree of Candidate of Technical Sciences / Taganrog, 2005

10. Sukhinov A.I., Sukhinov A.A., Kirilchik S.V. 3D Model of Diffusion-Advection-Aggregation Suspensions in Water Basins and Its Parallel Realization Book of Abstacts. The International Conf. Parallel Computational Fluid Dynamics 2004, May 24-27, Gran Canaria, Spain, pp. 189-192.

11. Sukhinov A.I., Sukhinov A.A., Kirilchik S.V. 3D Model of Bottom Sediment Transport Due to Miner's Operation. // Abstracts 7th International Conference Mathematical Modelling and Analysis, May31June 2, 2002, Kaariku, Estonia, p. 58.

\section{Authors:}

Sukhinov Alexander, Don State Technical University (1st Gagarin Square, Rostov-on-Don, Russian Federation), corresponding Member of the Russian Academy of Sciences, Doctor of Science in Physics and Maths, Professor 
UDC 519.6

10.23947/2587-8999-2021-1-1-1-9

\title{
ПРЕДСКАЗАТЕЛЬНОЕ МОДЕЛИРОВАНИЕ ПРОЦЕССА ТРАНСПОРТА ВЗВЕСЕЙ ПРИ РАЗЛИЧНЫХ СЦЕНАРИЯХ ИЗВЛЕЧЕНИЯ ЖЕЛЕЗОМАРГАНЦЕВЫХ КОНКРЕЦИЙ СО ДНА ТИХОГО ОКЕАНА
}

\author{
А. В. Сухинов ${ }^{1}$, А. А. Сухинов ${ }^{2}$, С.В Кирильчик ${ }^{2}$ \\ ${ }^{1}$ Донской государственный технический университет, Ростов-на-Дону, Россия \\ ${ }^{2}$ Южный федеральный университет, филиал в г. Геленджике, Россия \\ $\square$ sukhinov@gmail.com
}

Статья посвящена математическому моделированию распространения взвесей в восточной части Тихого океана для различных сценариев извлечения железомарганцевых конкреций. Модель распространения взвесей, имеющих сложный гранулометрический состав, способных взаимодействовать в водной среде, учитывает микротурбулентную диффузию взвесей, обусловленную турбулентным движением водной среды и конвекцию взвесей, вызванную адвективным движением водных масс в океане; гравитационное осаждение взвесей под действием на силы тяжести; взаимные переходы между различными фракциями, составляющими взвесь; взаимодействие частиц со дном и со свободной поверхностью.

Ключевые слова: железомарганцевые конкреции, гравитационное осаждение взвесей, микротурбулентная диффузия адвективное движение

\section{Авторы:}

Сухинов Александр Иванович, Донской государственный технический университет (344000 Ростов-на-Дону, пл. Гагарина, д. 1), член-корреспондент РАН, доктор физико-математических наук, профессор 